\title{
Interphase cytogenetics using biotin and digoxigenin labelled probes: III Increased sensitivity and flexibility for detecting HPV in cervical biopsy specimens and cell lines
}

\author{
C S Herrington, A K Graham, J O’D McGee
}

\begin{abstract}
A monoclonal antibody to digoxin enabled sandwich techniques to be used for the detection of hybridised digoxigenin labelled probes in cultured cells and paraffin wax sections. This system has greater flexibility than alkaline phosphatase conjugated polyclonal antidigoxigenin antibody and permits the use of alternative detector enzymes, such as horseradish peroxidase and fluorescence labels. The APAAP detection system that does not require the use of biotin can also be used in situations where endogenous biotin is a problem. The low level of background staining combined with precise substrate deposition of the amplified peroxidase system gives higher sensitivity and resolution. This permits localisation of closely adjacent chromosomal loci in interphase nuclei. The most sensitive peroxidase based digoxigenin detection system visualises two and a half to 12 copies of human papillomavirus (HPV) per nucleus. This system is also suitable for the analysis of low copy number HPV infection of cervical tissues.
\end{abstract}

Interphase cytogenetics encompasses, among other things, visual discrimination of individual chromosomes or genes in interphase nuclei. ${ }^{1-3}$ This has previously been performed by fluorescence ${ }^{45}$ and more recently by enzyme based chromogenic procedures using biotin and digoxigenin labelled probes. ${ }^{6-8}$ During the course of the latter work, it became apparent that the detection systems for biotin or digoxigenin labelled probes using alkaline phosphatase based detection systems did not give sufficient resolution to discriminate between closely adjacent chromosomal loci.

Digoxigenin labelled probes have been used both as alternatives and in addition to biotin labelled probes in non-isotopic in situ hybridisation (NISH) ${ }^{67}$ The main advantage of digoxigenin over biotin labelled probes for NISH is that digoxigenin (a plant alkaloid analogue), unlike biotin, is not present constitutively in mammalian cells. Hence, in immunohistochemical detection systems, digoxigenin does not generate endogenous background to the same extent as biotin. Digoxigenin labelled probes, however, are less sensitive than biotinylated probes using single step detection methods. ${ }^{6}$ The sensitivity of detection procedures can be enhanced using antibody sandwich techniques using a linker antibody to bridge between antibody directed against reporter molecule and an enzyme conjugate. ${ }^{9} \mathrm{~A}$ refinement of this concept is to use biotinylated antibodies, which can be used to bridge between the first antibody, and an avidin enzyme conjugate. $^{10}$ This gives increased sensitivity due to the high affinity of avidin for biotin (dissociation constant $=10^{-15}$ $M)$ and improved specificity when the first antibody is of monoclonal type.

Digoxigenin, the aglycone derivative of the cardiac glycoside digoxin, has high affinity for antibodies to digoxin. ${ }^{11-13}$ This suggested to us that the antibodies which have been developed for the monitoring and treatment of clinical digoxin toxicity would increase the sensitivity of detection of digoxigenin labelled probes in NISH.

The aims of this investigation were: (1) to develop systems of high sensitivity and resolution for digoxigenin labelled probes which are applicable to interphase cytogenetics-for the latter, CaSki and HeLa cells were used as a model system; and (2) to adapt detection systems for digoxigenin labelled probes so that they are more sensitive and flexible for detection of genes in archival biopsy specimens.

\section{Methods}

All chemicals were obtained from Sigma (UK) or BDH (UK) unless otherwise stated.

The HPV6 probe was the amp2 fragment cloned into pBR322, ${ }^{14}$ the HPV16 probe the whole viral genome in pAT $153,{ }^{15}$ and HPV 18 the whole viral genome in pBR322. ${ }^{16}$ Biotin and digoxigenin were incorporated into plasmid DNAs by nick translation, and the degree of labelling and size of fragments were as previously described. ${ }^{617}$

Paraffin wax sections were prepared and nucleic acids unmasked as previously described. ${ }^{6}$

HeLa 229 cells (ATCC, USA) were grown to confluence in $80 \mathrm{~cm}^{2}$ flasks in RPMI 1640 medium (Gibco, UK) supplemented with Lglutamine $(1 \times$; Gibco, UK); penicillin/ 
streptomycin (1 $\times$; Gibco, UK); and 20\% fetal calf serum (Gibco, UK). Detachment was achieved using trypsin/EDTA solution (Gibco, UK) and the cells were pelleted at $600 \times g$. After two washes in PBS the cells were fixed in $10 \%$ formalin, embedded in agar, and processed to paraffin wax in the usual way. Sections of $4 \mu \mathrm{m}$ were cut and unmasked using proteinase $\mathrm{K}$ at a concentration of $1 \mathrm{mg} / \mathrm{ml}$ in PBS for 15 minutes at $37^{\circ} \mathrm{C}$.

CaSki cells were grown onto slides, fixed in paraformaldehyde, and nucleic acids unmasked as previously described. ${ }^{6}$

\section{HYBRIDISATION}

Aliquots of hybridisation mix $(8 \mu \mathrm{l})$ containing $2 \mathrm{ng} / \mu \mathrm{l}$ of biotin or digoxigenin labelled HPV6, HPV16, or HPV18 were added to each well on multispot slides which were covered with a $14 \mathrm{~mm}$ glass coverslip (Chance, UK) and the slides placed in a moist Terasaki plate. Hybridisation mix consisted of $50 \%$ formamide, $5 \%$ dextran sulphate, $2 \times$ SSC, and 0.05 $\mathrm{mol} / \mathrm{l}$ TRIS-HCl, $\mathrm{pH} 7 \cdot 3 ; 1 \times \mathrm{SSC}=0.15$ $\mathrm{mol} / 1$ sodium chloride, $0.015 \mathrm{~mol} / 1$ sodium citrate. Sections and probes were simultaneously denatured at $95^{\circ} \mathrm{C}$ for 15 minutes on a solid stainless steel plate in a hot air oven and then hybridised at $42^{\circ} \mathrm{C}$ for 2 hours.

\section{DETECTION OF HYBRIDISATION SIGNAL}

All antibody/avidin incubations were carried out for 30 minutes at $22^{\circ} \mathrm{C}$ unless otherwise stated. Slides were washed in three changes of 4 $\times$ SSC at $22^{\circ} \mathrm{C}$ (five minutes each change), soaked in blocking agent TBT $(0.05 \mathrm{~mol} / 1$ TRIS- $\mathrm{HCl}, 0 \cdot 10 \mathrm{~mol} / 1$ sodium chloride $(\mathrm{pH}$ $7 \cdot 2)$ containing $3 \%(\mathrm{w} / \mathrm{v})$ bovine serum albumin and $0.05 \%$ Triton $100(\mathrm{v} / \mathrm{v}))$ at $22^{\circ} \mathrm{C}$ for 10 minutes. Subsequent visualisation of signal was determined by the reporter molecule.

\section{Biotin labelled probes}

(a) Single step procedure Sections were incubated in avidin-alkaline phosphatase or avidin-peroxidase (Dako, UK) diluted 1 in 100 in TBT. Unbound conjugate was removed by washing for five minutes twice in $50 \mathrm{mM}$ TRIS- $\mathrm{HCl}, 10 \mathrm{mM} \mathrm{NaCl}, \mathrm{pH} 7 \cdot 2$ (TBS), and the sections incubated in the appropriate substrate.

(b) Three step procedure Sections were incubated first in monoclonal mouse antibiotin (Dako, UK) diluted 1 in 50 in TBT, washed in TBS (twice at 10 minutes each), and then in biotinylated rabbit anti-mouse $\left(F\left(\mathrm{ab}^{\prime}\right)_{2}\right.$ fragment, Dako, UK). After washing in TBS, the third incubation was in either avidin alkaline phosphatase (bio-3-A/N), or streptavidin peroxidase (Dako, UK) (bio-3-P/C). The former was diluted 1 in 50 and the latter 1 in 100 in TBT containing 5\% non-fat milk. After washing in TBS, sections were incubated in the appropriate substrate (see below).

\section{Digoxigenin labelled probes}

(a) Single step procedure Sections were incubated in alkaline phosphatase conjugated antidigoxigenin (Boehringer, Germany) diluted 1 in 600 in TBT, washed in TBS, and the signal was developed using NBT/BCIP (see below).

(b) Three step procedure Sections were incubated in monoclonal antidigoxin (Sigma, UK) diluted 1 in 10000 in TBT. Subsequent detection was as for the three step detection of biotinylated probes, with second incubation in biotinylated rabbit anti-mouse $\left(F\left(\mathrm{ab}^{\prime}\right)_{2}\right.$ fragment) and the third incubation in avidinperoxidase (dig-3-P/C) or avidin-alkaline phosphatase (dig-3-A/N).

(c) APAAP system Slides were incubated in monoclonal antidigoxin as in (a), followed by rabbit anti-mouse immunoglobulin (Dako, UK), diluted 1 in 50 in TBT, then APAAP complex (Dako, UK) diluted 1 in 50 in TBT. Signal was developed using NBT/BCIP.

(d) Fluorescence detection Slides were treated as for the three step detection method in (b) except that streptavidin-fluorescein isothiocyanate (Dako, UK) was used in the final step. Optimal results were obtained with a dilution of 1 in 20 of the fluorescent conjugate in TBT containing $5 \%$ non-fat milk.

\section{SUBSTRATE PREPARATION}

Nitroblue tetrazolium/5-bromo-4-chloro3-indolyl phosphate (NBT/BCIP) and aminoethylcarbazole (AEC) were made as previously described. ${ }^{618}$ Diaminobenzidine (DAB) was diluted to $0.5 \mathrm{mg} / \mathrm{ml}$ in distilled water and stored in $5 \mathrm{ml}$ aliquots at $-20^{\circ} \mathrm{C}$. Hydrogen peroxide was added to DAB (final concentration $0.3 \%$ ) immediately before use. After probe detection slides were air dried at $42^{\circ} \mathrm{C}$ and mounted in glycerol jelly (for enzyme/ chromogen reactions). For fluorescence preparations, PBS/glycerol (1:9 v/v) containing $2.3 \%$ diazobicyclo-octane (DABCO) (Sigma, UK) was used.

Frequency distributions were compared using the two tailed Mann-Whitney $U$ test with a correction for tied values.

\section{Results}

The results of single step detection methods for biotin and digoxigenin probes have previously been reported. ${ }^{67}$ These were less sensitive than the three step procedures described below.

COMPARATIVE SENSITIVITY AND RESOLUTION OF DIGOXIGENIN AND BIOTIN IN INTERPHASE CELLS The three step peroxidase AEC detection method for digoxigenin labelled probes (dig-3$\mathrm{P} / \mathrm{C}$ ) produced very low background staining and enhanced resolution in CaSki and HeLa cells (figs 1 and 2). Discrete HPV signals were considerably more easily resolved when compared with the three step alkaline phosphatase NBT/BCIP detection system for digoxigenin (dig-3-A/N) (fig 1); the latter is the counterpart of the most sensitive system we have developed hitherto. ${ }^{19}$

An estimate of the absolute sensitivity of the dig-3-P/C method (fig 3) can be made by analysis of the frequency distribution of dots per interphase nucleus in CaSki cells. The median number of dots per nucleus is nine. Up 


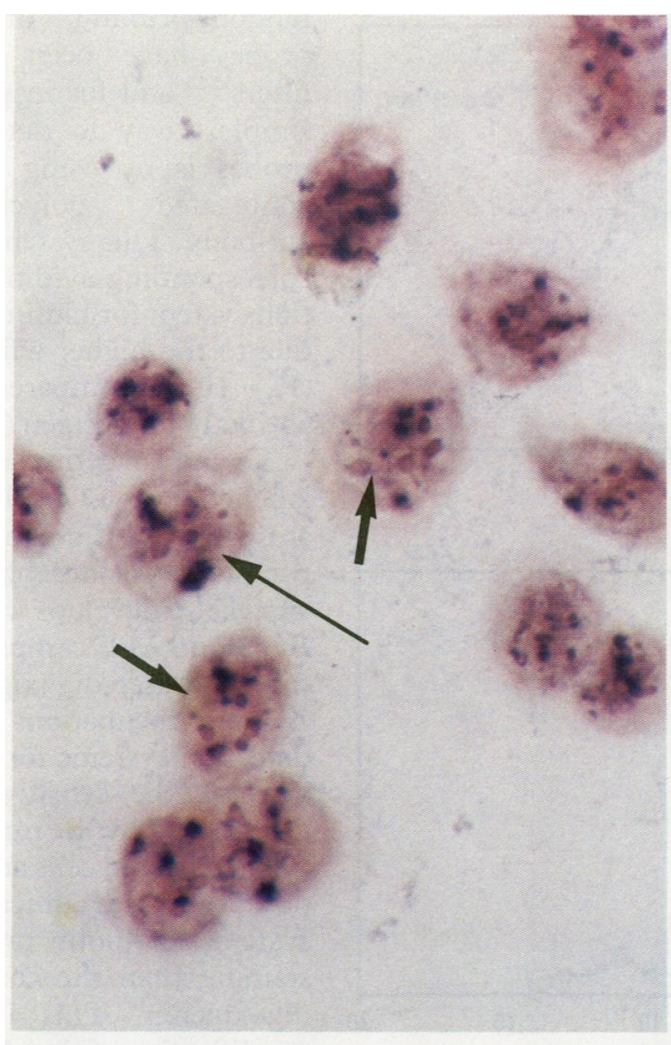

(A)

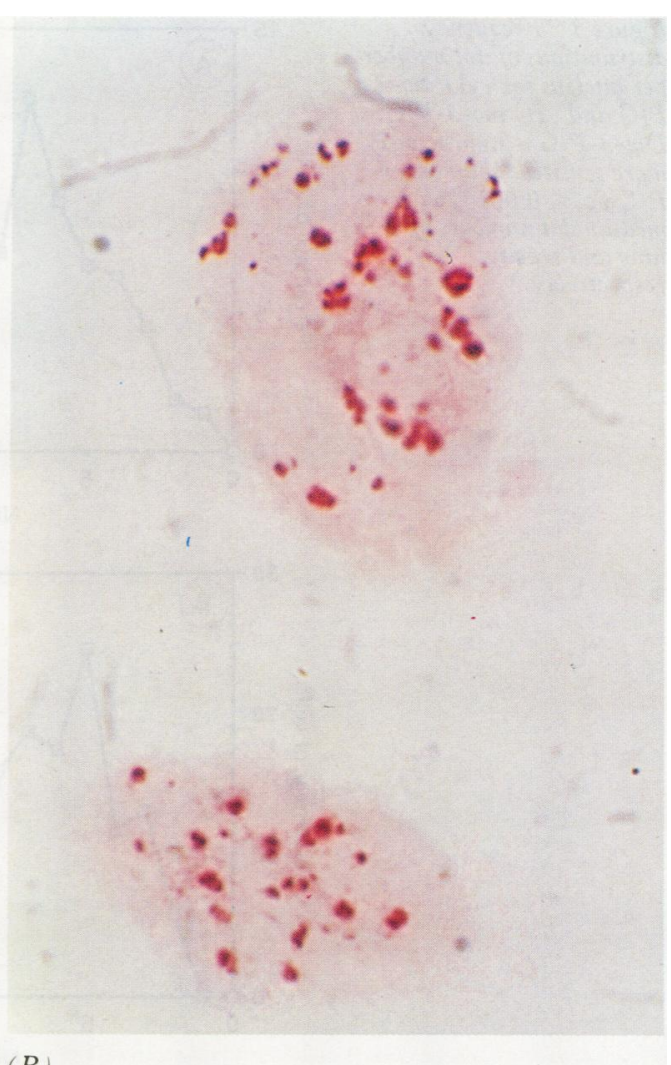

(B)
Figure 2 HeLa cells fixed in formalin and embedded in paraffin wax were hybridised with digoxigenin labelled HPV 18 and detected using dig-3-P/C. Four discrete signals (large arrow) can be seen within a single nucleus. Note that signals are present within other nuclei but that some are out of the plane of focus.

\section{Digoxigenin labelled probes}

The amplified procedure for the detection of digoxigenin using alkaline phosphatase with NBT/BCIP as substrate (dig-3-A/N) gave a signal in a greater number of cells compared with the comparable three step alkaline phosphatase system for biotin detection (bio-3-A/ N) (fig 4). The background produced by dig-3$\mathrm{A} / \mathrm{N}$ is significantly less than that produced by bio-3-A/N and the signal intensity is enhanced to a greater degree using digoxigenin compared with biotin (fig 4). Clear signal within almost all parabasal cells is present with digoxigenin labelled probes (fig 4A). The signal to noise ratio of digoxigenin labelled probes is superior to that of biotinylated probes-compare figs $4 \mathrm{~A}$ and $4 B$.

Using the three step peroxidase AEC detection system for the detection of digoxigenin labelled HPV16 (dig-3-P/C) in lesions defined histopathologically as CIN3, signal can be seen in all layers of the epithelium, including the basal layer (fig 5). Notably, the morphology of this signal is different from that obtained by $\mathrm{NISH}$ analysis of wart virus infection with mild atypia (fig 4). The combination of the substrate AEC with haematoxylin counterstaining aids interpretation.

The APAAP procedure produced a clear signal with little background (data not shown), but it was less sensitive than the procedure used in fig 4 as judged by both the number of positive cells and the fact that parabasal cells were not labelled.

Fluorescence detection of digoxigenin labelled probes also produced satisfactory 
Figure 3 Frequency distributions of dot number per nucleus for $(A)$ dig-3$P / C$ and $(B)$ bio-3-P/C. Dig-3-P/C is significantly more sensitive than bio-3$P / C(p<0.001)$, with median dot numbers of nine and seven, respectively.


results, with low background staining of surrounding connective tissue (data not shown). This procedure, however, was less sensitive as signal was not detected within parabasal cells.

\section{Discussion}

Digoxigenin has been used to label probes by terminal labelling of oligonucleotides, ${ }^{22}$

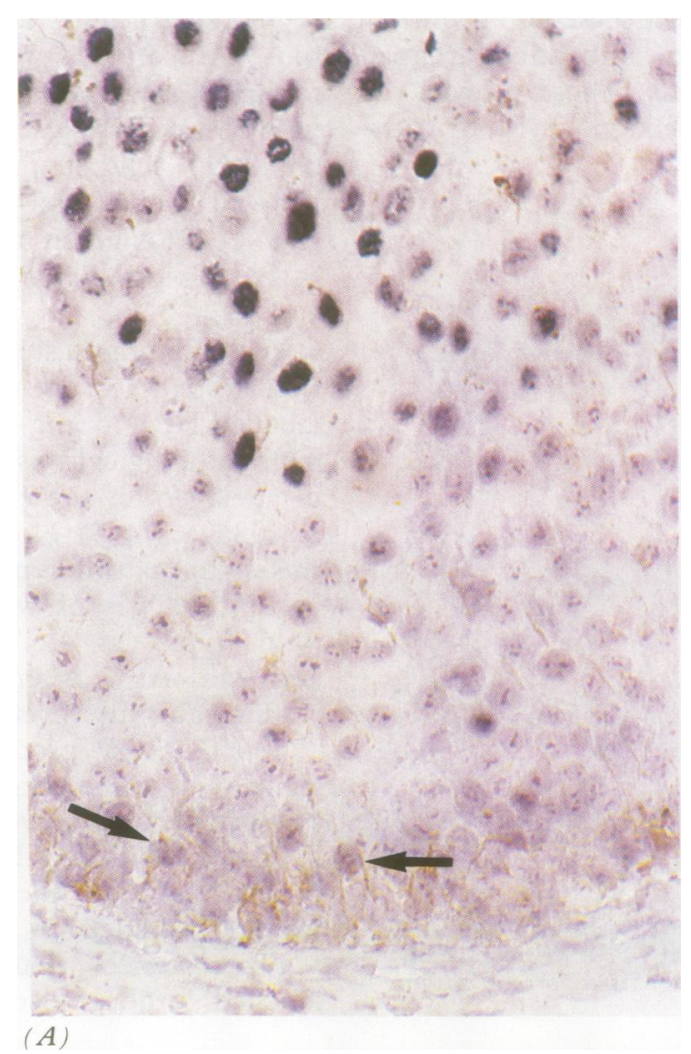

random priming, ${ }^{23}$ or nick translation. ${ }^{6}$ These probes have been used on nitrocellulose filters ${ }^{22}{ }^{23}$ and for in situ hybridisation. ${ }^{67}$ The simplest way to detect digoxigenin labelled probes is by using an alkaline phosphatase conjugated polyclonal antidigoxigenin antibody. This system is less sensitive than the corresponding avidin based single step detection system for biotin, ${ }^{6}$ a difference likely to be due to the higher affinity of avidin for biotin $\left(K_{D} 10^{-15}\right)$ compared with the affinity of antibody for antigen $\left(\mathrm{K}_{\mathrm{D}} 10^{-12}\right.$ at best).

To improve the sensitivity of digoxigenin labelled probes we have used a monoclonal antibody to digoxin.: As shown here, this produces considerably greater sensitivity. The signal also develops within minutes with NBT/ BCIP and AEC compared with an hour or more for single step digoxigenin detection and up to 16 hour incubations in NBT/BCIP in some detection systems for biotin. ${ }^{24}$ These methods increase the sensitivity of these probes as determined by the number of HPV signals per cell in cultured cells and by the number of HPV positive cells in clinical samples. The detection systems for biotin produce more background staining than the corresponding systems for digoxigenin. This is likely to be due to amplification of signal from endogenous biotin. By increasing the number of rounds of amplification of digoxigenin, the signal can be enhanced still further but, as this requires the use of an anti-biotin antibody and an avidin conjugate, the background staining is correspondingly increased. Nevertheless, amplified detection systems for digoxigenin amplify endogenous biotin by one round fewer than the corresponding system for biotin.

Advantages of the peroxidase-AEC system are both its high degree of resolution and the ease of interpretation of preparations counter-

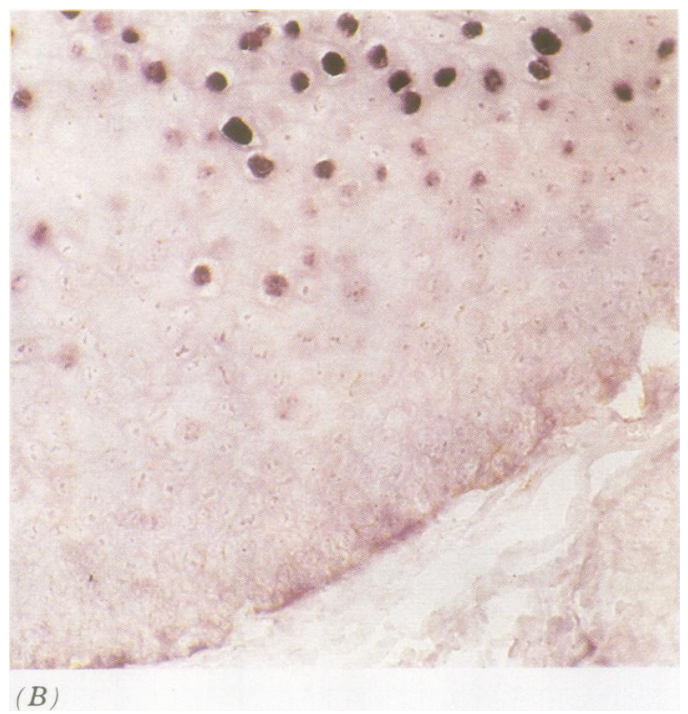

Figure 4 Sections of a condyloma acuminatum were probed with $(A)$ digoxigenin labelled and $(B)$ biotin labelled HPV6, detected using the three step methods dig-3- $A / N$ and bio-3- $A / N$, respectively. Parabasal cells are positive only with the digoxigenin labelled probe (arrows). Note the low level of background staining in the subjacent stroma in $(A)$. The biotinylated probe produces greater background staining in the region of the basement membrane rendering interpretation impossible. 


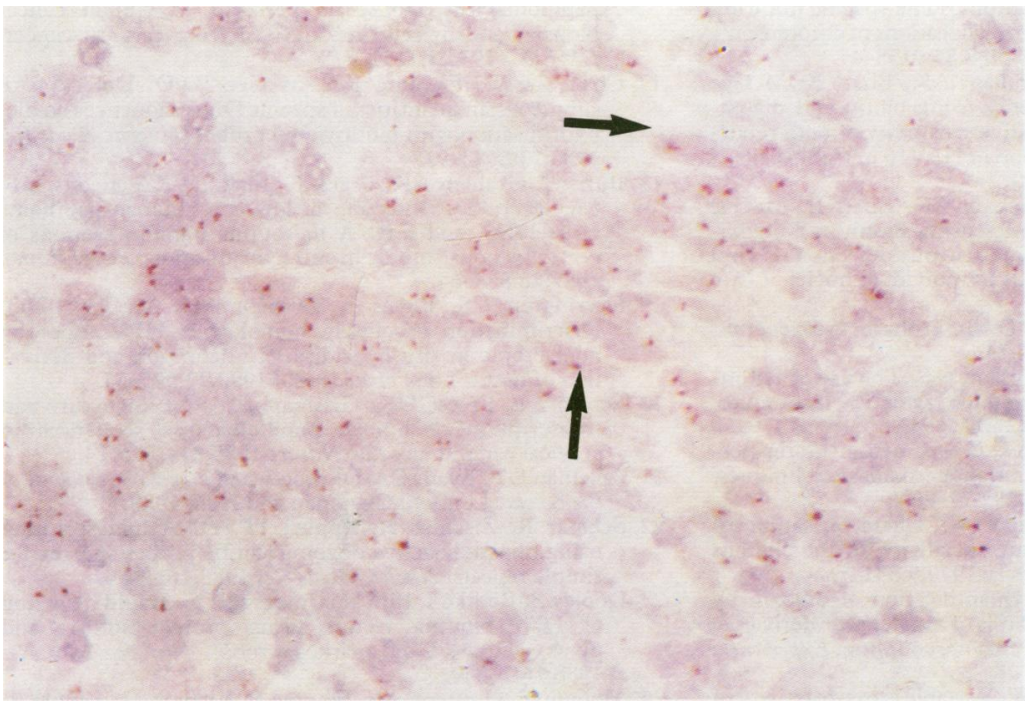

Figure 5 A biopsy specimen of CIN 3 probed with digoxigenin labelled HPV16 and detected using the peroxidase AEC system (dig-3-P/C). Note that signal is present in basal cells (large arrow).
In routine cervical biopsy specimens, the three step digoxigenin system is clearly the most sensitive developed for clinical practice. An HPV signal is evident in almost all parabasal cells. It is of note that the morphology of the signal (single dots) obtained in the biopsy specimen shown in fig 5 resembles that seen in CaSki and HeLa cells, in which the viral genomes are known to be integrated. ${ }^{25} 26 \mathrm{It}$ is tempting to speculate that this NISH signal morphology is indicative of viral integration and this is under investigation by routine molecular biological techniques in this laboratory.

APAAP and fluorescence detection of digoxigenin labelled probes can be performed by minor modification to the three step detection system. These may be useful in clinical laboratories for routine screening by NISH of $\mathrm{HPV}$ in cervical biopsy specimens but they are less sensitive than the methods described in detail above. It should be noted, however, that the APAAP system has the advantage that it does not require biotin. This may be useful in tissues where endogenous biotin creates high background.

Overall, the preferred methods are therefore: (i) three step alkaline phosphatase NBT/BCIP detection of digoxigenin labelled probes where high sensitivity and low background but not high signal resolution are required; (ii) three step peroxidase AEC detection of digoxigenin where high sensitivity, high resolution, and low background are required in addition to nuclear counterstaining.

In conclusion, HPV probes labelled with digoxigenin can be detected using long established monoclonal antibodies to digoxin. This permits amplification of the signal produced by these probes to a degree that detects low copy number viral infection in cell lines and routine clinical samples. Flexibility is also enhanced in that digoxigenin detection can be achieved with horseradish peroxidase, fluorescence and APAAP systems. The latter has the advantage that it does not require biotin. The enhanced sensitivity and resolution also make digoxigenin an attractive label for interphase cytogenetics and for the detection of HPV in cervical disease.

CSH is a CRC Clinical Research Fellow and holds a Junior Research Fellowship at Green College, Oxford. This work was supported by grants to J O'D McG from the Cancer Research Campaign (UK). absolute sensitivity of 40 viral genomes for biotin and 30 for digoxigenin detection using the amplified peroxidase methods, given that the total number of copies of HPV per CaSki cell nucleus is about $270 .^{6}$ This measure is, however, an underestimate as it assesses relative sensitivity more accurately than absolute sensitivity, ${ }^{6}$ and as can be seen from fig 2 , the presence of multiple signals in HeLa cell nuclei using this system suggests that the sensitivity is greater. Indeed, it has been estimated that HeLa cells contain 10-50 copies of HPV 18. ${ }^{20}$ As four NISH signals were visualised in paraffin wax embedded HeLa cells, an estimate of the sensitivity of this detection system is two and a half to 12 viral copies in routinely processed material.

Burns J, Chan VT-W, Jonasson JA, Fleming KA, Taylor S, McGee JO'D. Sensitive system for visualising biotinylated DNA probes hybridised in situ: rapid sex determination in intact cells. J Clin Pathol 1985;38: 1085-92.

2 Cremer T, Landegent J, Bruckner A, et al. Detection of chromosome aberrations in the human interphase nucleus chromosolse aberrations in the human interphase nucleus and non-radioactive in situ hybridisation techniques: and non-radioactive in situ hybridisation techniques: 1986;74:346-52.

3 Bhatt B, McGee JO'D. Chromosomal assignment of genes. In: Polak J, McGee JO'D, eds. In situ hybridisation: principles and practice. Oxford: OUP, 1990:149-64.

4 Hopman AHN, Ramaekers FCS, Raap AK, et al. In situ hybridisation as a tool to study numerical chromosome aberrations in solid bladder tumours. Histochemistry 1988; 89:307-16

5 Pinkel D, Landegent J, Collins C, et al. Fluorescence in situ 
hybridisation with human chromosome specific libraries: Detection of trisomy 21 and translocations of chromosome 4. Proc Natl Acad Sci USA 1988;85:9138-47.

6 Herrington CS, Burns J, Graham AK, Bhatt B, McGee JO'D. Interphase cytogenetics using biotin and digoxiJO'D. Interphase cytogenetics using biotin and digoxi-
genin labelled probes I: relative sensitivity of both reporter molecules for the detection of HPV 16 in CaSki cells. $J$ ter molecules for the detection

7 Herrington CS, Burns J, Graham AK, Bhatt B, McGee JO'D. Interphase cytogenetics using biotin and digoxigenin labelled probes II: simultaneous detection of viral and mammalian nucleic acids in individual nuclei. J Clin Pathol 1989;42:601-6.

8 Herrington CS, McGee JO'D. Interphase cytogenetics. Neurochem Res 1990;15:467-74.

9 Guesdon J-L, Ternynck T, Avrameas S. The use of avidinbiotin interaction in immunoenzymatic techniques. biotin interaction in immunoenzymat

$10 \mathrm{Hsu}$ S-M, Raine L, Fanger H. Use of avidin-biotin-peroxidase complex $(\mathrm{ABC})$ in immunoperoxidase techniques. $J$ Histochem Cytochem 1981;29:577-80.

11 Smith JW, Butler VP, Haber E. Characterisation of antibodies of high affinity and specificity for the digitalis glycoside digoxin. Biochemistry 1970;9:331-7.

12 Monji N, Ali H, Castro A. Quantification of digoxin by enzyme immunoassay: synthesis of a maleimide derivative of digoxigenin succinate for enzyme coupling. Experientia 1980;36:1141-3.

13 Valdes R, Brown B, Graves SW. Variable cross-reactivity of digoxin metabolites in digoxin immunoassay. $\mathrm{Am} \mathrm{J} \mathrm{Clin}$ Pathol 1984;82:210-13.

14 De Villiers E-M, Gissmann L, Zur Hausen H. Molecular cloning of viral DNA from human genital warts. $J$ Virol 1981;40:932-5.

15 Dürst M, Gissmann L, Ikenberg H, Zur Hausen H. A papillomavirus DNA from a cervical carcinoma and its prevalence in cancer biopsy samples from different geographical regions. Proc Natl Acad Sci USA 1983; 80:3812-15.

16 Boshart ML, Gissmann L, Ikenberg $\mathrm{H}$, Kleinheinz A, Scheurlen $W$, Zur Hausen $H$. A new type of papillomavirus DNA, its presence in genital cancer biopsies and in cell lines derived from cervical cancer. EMBO J 1984;3:1151-7.

17 Chan VT-W, Fleming KA, McGee JO'D. Detection of subpicogram quantities of specific DNA sequences on blot hybridisation with biotinylated probes. Nucleic Acids Res 1985;13:8083-9

18 Burns J, Graham AK, Frank C, Fleming KA, Evans MF, McGee JO'D. Detection of low copy human papilloma virus DNA and mRNA in routine paraffin sections of cervix by non-isotopic in situ hybridisation. J Clin Pathol 1987;40:858-64.

19 Herrington CS, Burns J, Graham AK, McGee JO'D Discrimination of closely homologous HPV types by nonisotopic in situ hybridisation: definition and derivation of tissue Tms. Histochem J 1990;22:545-54.

20 Schwarz E, Freese UK, Gissmann L, et al. Structure and transcription of human papillomavirus sequences in transcription of human papillomavirus sequence

21 Coleman DV, Evans DMD. Biopsy pathology and cytology of the cervix. London: Chapman and Hall, 1988

22 Schafer R, Zischler H, Epplen JT. DNA fingerprinting using non-radioactive oligonucleotide probes specific for simple repeats. Nucleic Acids Res 1988;16:9344

23 Dooley S, Radtke J, Blin N, Unteregger G. Rapid detection of DNA-binding factors using protein-blotting and digoxygenine-dUTP marked probes. Nucleic Acids Res 1988;16:11839.

24 Mougin C, Guitteny AF, Fouque B, Viennet G, Teoule R, Bloch B. Histochemical detection of the messenger RNAs coding for calcitonin and calcitonin gene-related peptide coding for calcitonin and calcitonin gene-related peptide
in medullary carcinomas of the thyroid with radioactive in medullary carcinomas of the thyroid with radioactive
and biotinylated oligonucleotide probes. J Pathol 1990; and biotiny 160 : $187-94$.

25 Popescu NC, DiPaolo JA, Amsbaugh SC. Integration sites of human papillomavirus 18 DNA sequences on HeLa cell chromosomes. Cytogenet Cell Genet 1987;44:58-62.

26 Mincheva A, Gissmann L, Zur Hausen H. Chromosomal integration sites of human papillomavirus DNA in three cervical cancer cell lines mapped by in situ hybridisation. Med Microbiol Immunol 1987;176:245-56. 